\title{
Three-dimensional shear wave velocity structure in the upper mantle beneath the Philippine Sea region
}

\author{
Yasuyuki Nakamura and Takuo Shibutani \\ Disaster Prevention Research Institute, Kyoto University, Gokasho, Uji, Kyoto 611-0011, Japan
}

(Received March 31, 1998; Revised July 23, 1998; Accepted July 27, 1998)

\begin{abstract}
The three-dimensional shear wave velocity structure in the upper mantle beneath the Philippine Sea was investigated with Rayleigh wave phase velocities in the periods 30-100 s. More than 900 Rayleigh wave phase velocity curves were obtained for this region with good path coverage. The phase velocity data were inverted for the phase velocity distribution maps in the Philippine Sea with 2-D tomographic technique without any a priori regionalization. The resolutions of the tomographic analysis were quite good in almost of the target region. The phase velocity maps were inverted for the 3-D shear wave velocity structure in the upper mantle down to $220 \mathrm{~km}$.

In the shallow depths lateral heterogeneities with short wavelength were seen in the shear wave velocity maps. This might be related with complicated surface structures. In the middle depths the shear wave velocity was well correlated to the main tectonic features seen at the surface and well explained by the evolution history of the Philippine Sea. The older western Philippine Sea had higher shear wave velocities than the younger eastern Philippine Sea. In the western Philippine Sea the central basin ridge, which is the youngest in this area, showed the low velocity anomaly. This is supported by the fact that the West Philippine Basin was formed in this area. In the depths 150-200 km the low velocity anomaly was dominant inside the Philippine Sea, which might suggest the existence of the mantle return flows. The thickness of the lithosphere in the south of the West Philippine Basin reached about $100 \mathrm{~km}$, which is much thicker than the results of previous studies for this region.
\end{abstract}

\section{Introduction}

The Philippine Sea is one of the marginal sea of the Pacific ocean. It covers the Philippine Sea plate, which is rather small in scale but contains very complicated tectonic settings in its own (see Fig. 1). For example there are three major basins; Shikoku Basin, Parece Vela Basin and West Philippine Basin, and ridges; Kyushu Palau Ridge, Daito Ridge, and trough; Mariana Trough. The relationships with surrounding areas (e.g. the Pacific ocean and the Eurasia continent) influence this complexities. The lateral variations of the upper mantle structure are also expected to be complicated and related to the surface structures mentioned above.

The evolution history of the Philippine Sea have been studied extensively using magnetic anomaly data, drilling core, and so on. The Philippine Sea is fundamentally divided into two regions bounded by the Kyushu-Palau Ridge. It is thought that these two regions were formed in different episodes of back-arc spreading (e.g. Seno and Maruyama, 1984).

In order to reveal the upper mantle heterogeneities, variations of seismic velocities were studied vigorously since 1980s in global scale (e.g. Masters et al., 1982) and in regional scale (e.g. Suetsugu and Nakanishi, 1987). In the Philippine Sea region, studies for upper mantle seismic structures have been a few in number.

Kanamori and Abe (1968) was the first attempt to reveal the upper mantle structure in the Philippine Sea region.

Copy right (C) The Society of Geomagnetism and Earth, Planetary and Space Sciences (SGEPSS); The Seismological Society of Japan; The Volcanological Society of Japan; The Geodetic Society of Japan; The Japanese Society for Planetary Sciences.
Group velocity dispersion data of surface waves travelling through the central portion of the Philippine Sea were used to construct a one-dimensional (1-D) upper mantle shear wave model, ARC-1. Several studies have been done to reveal the lateral variations of the upper mantle structure in the Philippine Sea region since Kanamori and Abe (1968). Seekins and Teng (1977) studied on the laterally heterogeneous structure in the upper mantle beneath the Philippine Sea with using seismograms recorded at Guam which is the WWSSN station located at the eastern edge of the Philippine Sea. They regionalized the Philippine Sea plate into three sub regions according to its topographic features. Shiono et al. (1980) also made a surface wave analysis using group velocity dispersion data. They investigated waveforms which traversed western (West) and eastern (East) Philippine Sea. Senna et al. (1990) and Oda and Senna (1994) divided the Philippine Sea region and its marginal region into seven sub regions according to the topographic features and obtained a 1-D shear wave velocity structure for each sub region using group velocity dispersion data. As to body wave analysis, Iidaka et al. (1989) is the only study to investigate the lateral heterogeneity of the upper mantle in the Philippine Sea.

These studies on lateral heterogeneities in the upper mantle beneath the Philippine Sea region are summarized as follows: 1) the upper mantle in this region has heterogeneities which might be related to the topographic features, 2) the variations of lithospheric depth are interpreted in terms of the sea floor age and are well explained by the plate cooling model, 3) the heterogeneous structures might be extend down to the depths of $200-350 \mathrm{~km}$. However, all of these studies required a 


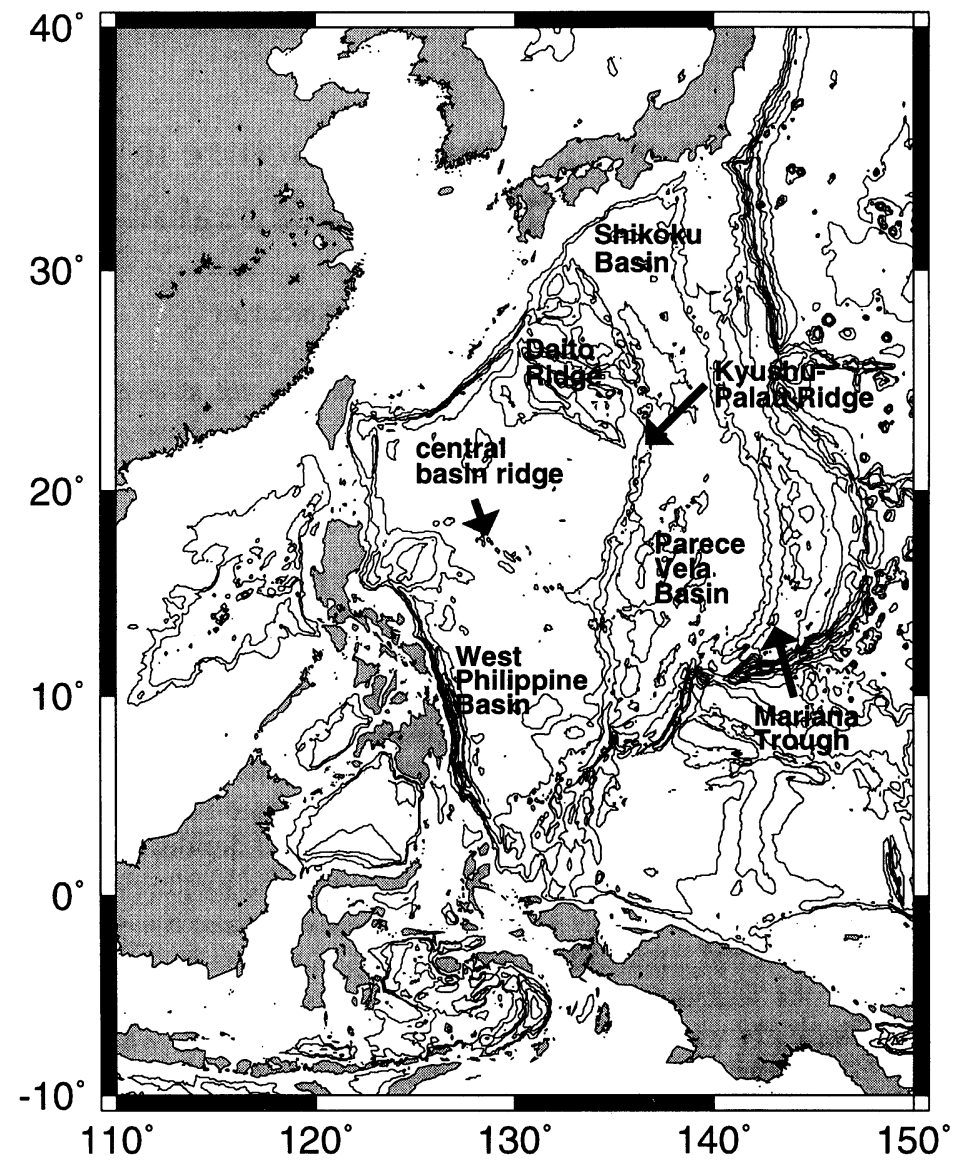

Fig. 1. Major features of the Philippine Sea. Contour interval $=1000 \mathrm{~m}$.

priori regionalizations. The a priori information might effect the results mentioned above. The lithosphere thicknesses of the obtained structures seem to be influenced by that of the reference model, especially the ARC-1 model.

Recently Kato and Jordan (1998) proposed a new 1-D model for the upper mantle of the Philippine Sea using body wave and surface wave data. Although the paths they used were limited to the western Philippine Sea region, their model had very thick (about $75 \mathrm{~km}$ ) lithosphere, which was much thicker than that expected from the plate cooling model (Kono and Yoshii, 1975).

Recent accumulation of broadband seismic records allows us to reveal the heterogeneous structures using a tomographic approach which requires no a priori regionalization. The variations of lithosphere thickness can be mapped from the detail seismic structure obtained three-dimensionally. Lebedev et al. (1997) inverted 281 vertical-component broad band waveforms recorded at Australia and around the Philippine Sea. They presented a three-dimensional shear wave velocity structure of the upper mantle beneath the Philippine Sea.

The aim of this study is to reveal the detail heterogeneous structure in the upper mantle beneath the Philippine Sea region without any a priori regionalization. The distributions of shear wave velocities are obtained using tomographic technique which requires no a priori regionalizations. The num- ber of the surface wave dispersion data used in this study is much larger than those in previous studies in the same region.

\section{Data}

The waveform data used in this study were recorded at broadband stations installed around the Philippine Sea (See Table 1 and Fig. 2). About 1400 broadband vertical component seismograms were collected for Rayleigh waves, which were generated by events occurred around the Philippine Sea and recorded at the stations also around the Philippine Sea. We extracted the minor-arc surface waves and analyzed them. Because the minor-arc surface waves sample only our target region, the interferences caused by the structure out of the Philippine Sea can be eliminated.

Each waveform was deconvolved by instrumental response and filtered in 6-50 $\mathrm{mHz}$ frequency range. Only the waveforms which were generated by events occurred at depths shallower than $100 \mathrm{~km}$ were used because higher modes might be prominent and might contaminate fundamental modes in the records of deeper events. The locations of 150 events used in this study were also shown in Fig. 2. We selected the waveforms which satisfied that propagation distance between the epicenter and the station was larger than $15^{\circ}$. Centroid moment tensor solutions provided by Harvard University were used for source parameters of earthquakes in this study. 
Table 1. List of the station used in this study.

\begin{tabular}{lrr}
\hline Code & Lat. & Lon. \\
\hline CHU & 35.63 & 140.11 \\
DAV & 7.09 & 125.57 \\
GUMO & 13.59 & 144.87 \\
HCH & 33.12 & 139.80 \\
HKY & 35.23 & 139.12 \\
ISG & 24.38 & 124.23 \\
JIZ & 34.91 & 139.00 \\
MAJO & 36.54 & 138.21 \\
OGS & 27.05 & 142.20 \\
SGN & 35.51 & 138.95 \\
SHK & 34.53 & 132.68 \\
SMZ & 34.99 & 138.52 \\
TATO & 24.98 & 121.49 \\
TKO & 35.66 & 139.29 \\
TOK & 35.69 & 139.76 \\
TSK & 36.21 & 140.11 \\
TYM & 34.97 & 139.85 \\
YCU & 35.33 & 139.62 \\
\hline
\end{tabular}

\section{Phase Velocity Measurement with Non-Linear Waveform Inversion}

Phase velocities of each waveform in the period range 30$100 \mathrm{~s}$ were calculated using a non-linear waveform inversion technique in the frequency domain developed by Trampert and Woodhouse (1995).

Let $D(\omega)$ be the Fourier transform of an observed waveform. Similarly $S(\omega)$ corresponds the Fourier transform of a synthetic waveform, which is synthesized by superposition of the normal modes calculated with a reference model. In this study, fundamental spheroidal modes from ${ }_{0} \mathrm{~S}_{10}$ to ${ }_{0} \mathrm{~S}_{450}$ were superposed for Rayleigh wave. The eigenfunctions of the spheroidal modes were computed using the program package DISPER80 (Saito, 1988). The observed waveform is related to the synthetic waveform as follows:

$$
D(\omega)=A(\omega) \exp \{-i \omega \Delta \delta s(\omega)\} S(\omega)
$$

where $A(\omega)$ is amplitude correction term, and $\delta s(\omega)$ is phase slowness perturbation with respect to the reference model. $\Delta$ is the distance between the epicenter and the station and $\omega$ is the angular frequency. Because the amplitude and the phase terms are independent on each other, Eq. (1) can be written as following:

$$
\begin{aligned}
|D(\omega)|= & A(\omega)|S(\omega)|, \\
\Re(D(\omega))= & A(\omega)\{\Re(S(\omega)) \cos (\omega \Delta \delta s(\omega)) \\
& +\Im(S(\omega)) \sin (\omega \Delta \delta s(\omega))\},
\end{aligned}
$$

\section{EVENTS AND STATIONS}

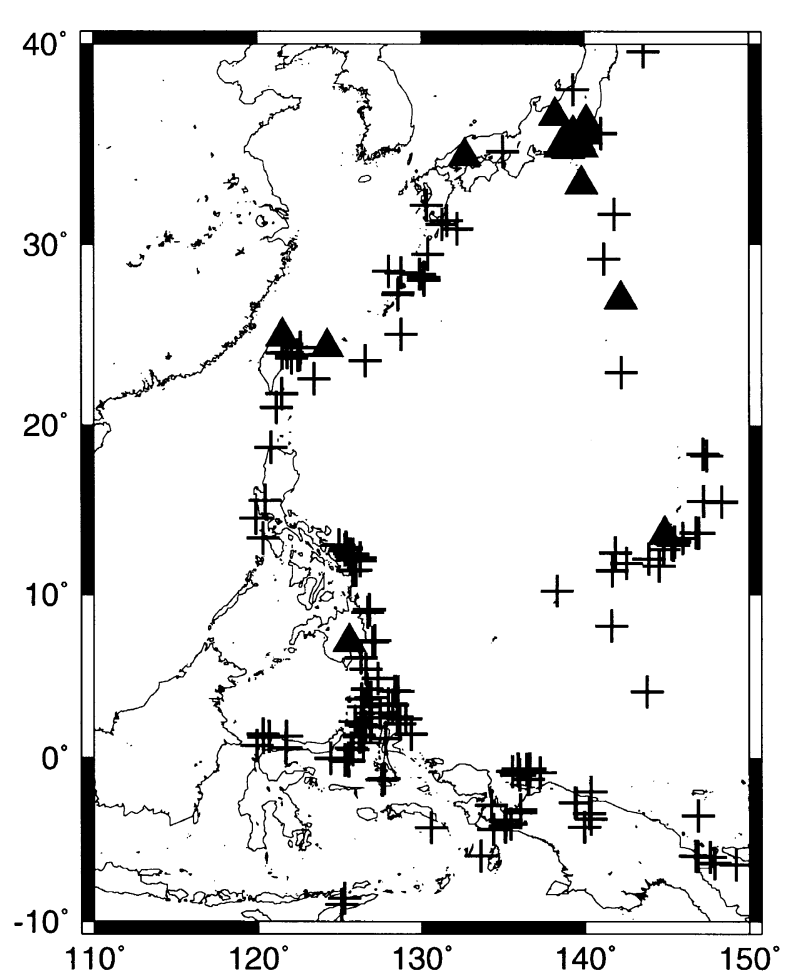

Fig. 2. Locations of the events (cross) and the stations (triangle).

$$
\begin{aligned}
\Im(D(\omega))= & A(\omega)\{\Im(S(\omega)) \cos (\omega \Delta \delta s(\omega)) \\
& -\Re(S(\omega)) \sin (\omega \Delta \delta s(\omega))\} .
\end{aligned}
$$

$A(\omega)$ and $\delta s(\omega)$ were represented with B-splines. The coefficients of the B-splines were solved by generalized non-linear inversion (Tarantola and Valette, 1982) with smoothing constraints. Details of the inversion are described in Trampert and Woodhouse (1995).

Prior to this inversion, each observed waveform was cut with group velocity windows $3.0-5.3 \mathrm{~km} / \mathrm{s}$ for Rayleigh waves. Synthesized waveforms were also cut with the same time windows as the corresponding observed waveforms. Signal-to-noise ratios were checked for the windowed "signal" waveforms. Waveforms windowed by the range of group velocity $5.0-5.3 \mathrm{~km} / \mathrm{s}$ were considered as "noise" waveforms. Maximum amplitudes of the envelopes of both "signal" and "noise" waveforms were calculated and the ratio of them was regarded as the signal-to-noise ratio in this study. If the signal-to-noise ratio is under a certain threshold, which was set to be 7 in this study, the waveform was rejected. About 200 waveforms were rejected because of the bad signal-to-noise ratio. Time-variable filter (Cara, 1973) was operated to the waveforms to suppress the contaminations by unexpected phases. The filter was designed with group velocity values for the reference model used in the waveform inversion. The effects of the attenuation factor $\mathrm{Q}$ was not modelled in our present study. Both synthetic and 
(a)
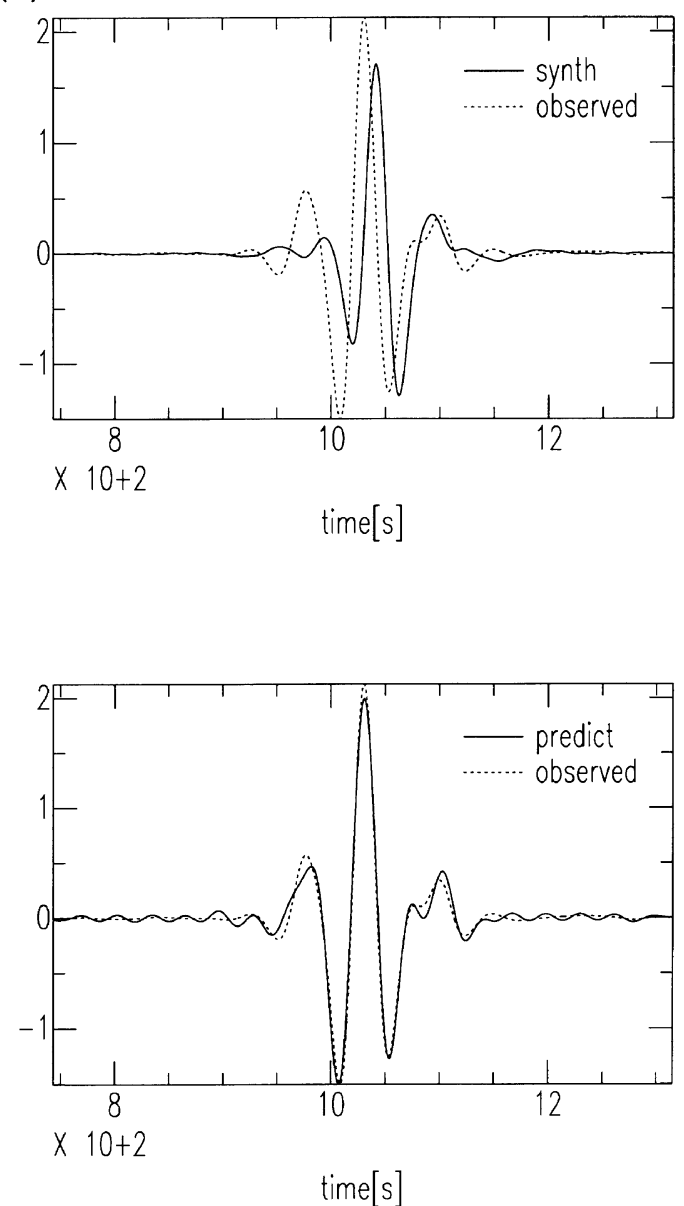

(b)
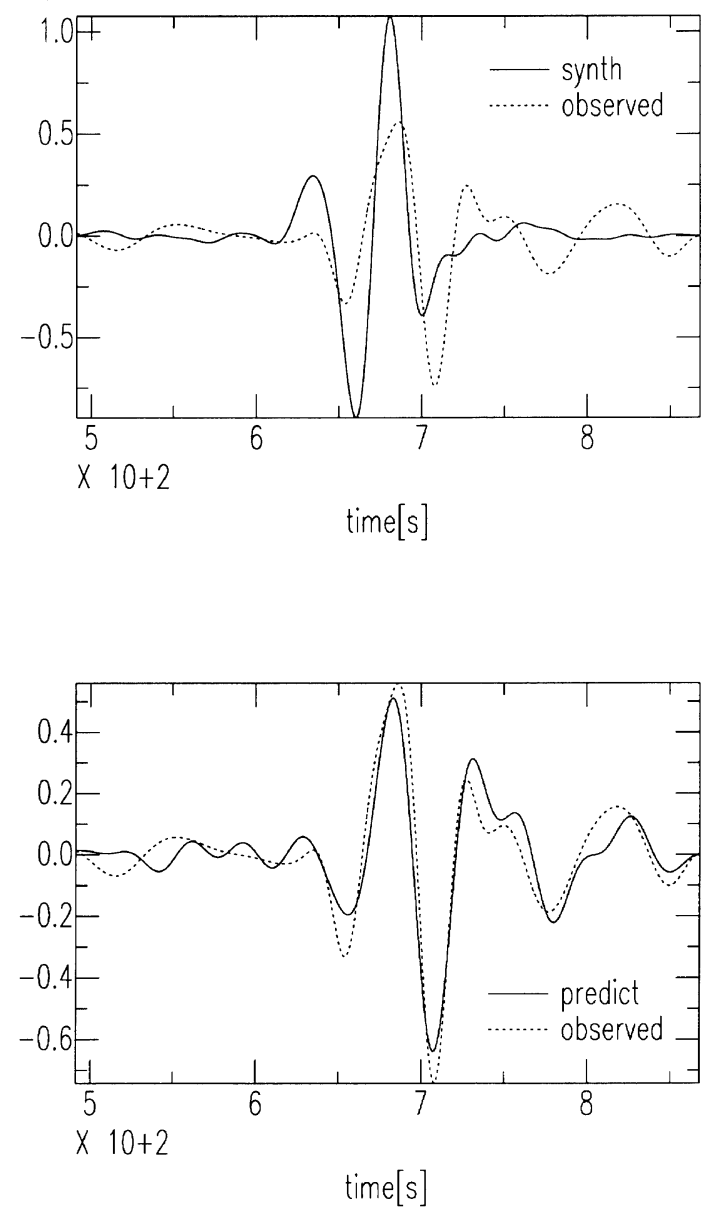

Fig. 3. Examples of the waveform inversion. (a) Example of the waveform which was inverted successfully in the waveform inversion. The upper figure shows the observed waveform (dotted line) and the synthetic waveform (solid line) predicted by the reference model. The lower figure shows the same observed waveform (dotted line) and the corrected synthetic waveform (solid line). The variance reduction was over $99 \%$ for this waveform. (b) Example of the waveform which was rejected after the waveform inversion. The upper and the lower figures are similar to Fig. 3(a). The variance reduction was $71 \%$ for this waveform.

observed waveforms were normalized by their root mean square amplitude.

The calculated phase velocities were selected with the following criteria:

1) Perturbations of the phase velocity with respect to the reference model are within $10 \%$ at all the frequencies analyzed in this study.

2) Perturbations of the group velocity with respect to the reference model are within $10 \%$ at all the frequencies.

3) Amplitude correction terms are determined within the range of $0.2-5.0$ at all the frequencies.

4) Total variance reduction in the waveform inversion is more than $85 \%$.

The criteria 1-3 are required mainly because the reference model should approximate the real structure well in the waveform inversion. The criterion 4 requires that the inverted model parameters, the coefficients of the B-splines, explain the observed data. The phase velocity dispersion data which survived all the criteria written above were used for the next tomographic analysis. Figure 3(a) shows an example of the waveforms which survived all the criteria. The inverted waveforms achieved good agreement with the observed ones. Figure 3(b) shows an example of the waveforms which was rejected by the criteria. The variance reduction in the waveform inversion was $71 \%$.

We could obtain 913 phase velocity curves with the PREM model (Dziewonski and Anderson, 1981) as the reference model including some modifications, which has slow shear wave velocities in the upper mantle. The shallower structures were also modified using the PEM-O model (Dziewonski et al., 1975).

\section{Phase Velocity Mapping with Tomographic Technique \\ 4.1 Tomographic analysis}

To investigate lateral heterogeneities in the upper mantle beneath the Philippine Sea, the obtained phase velocity curves were inverted to the phase velocity distribution maps for each period using 2-D tomographic technique. The block 


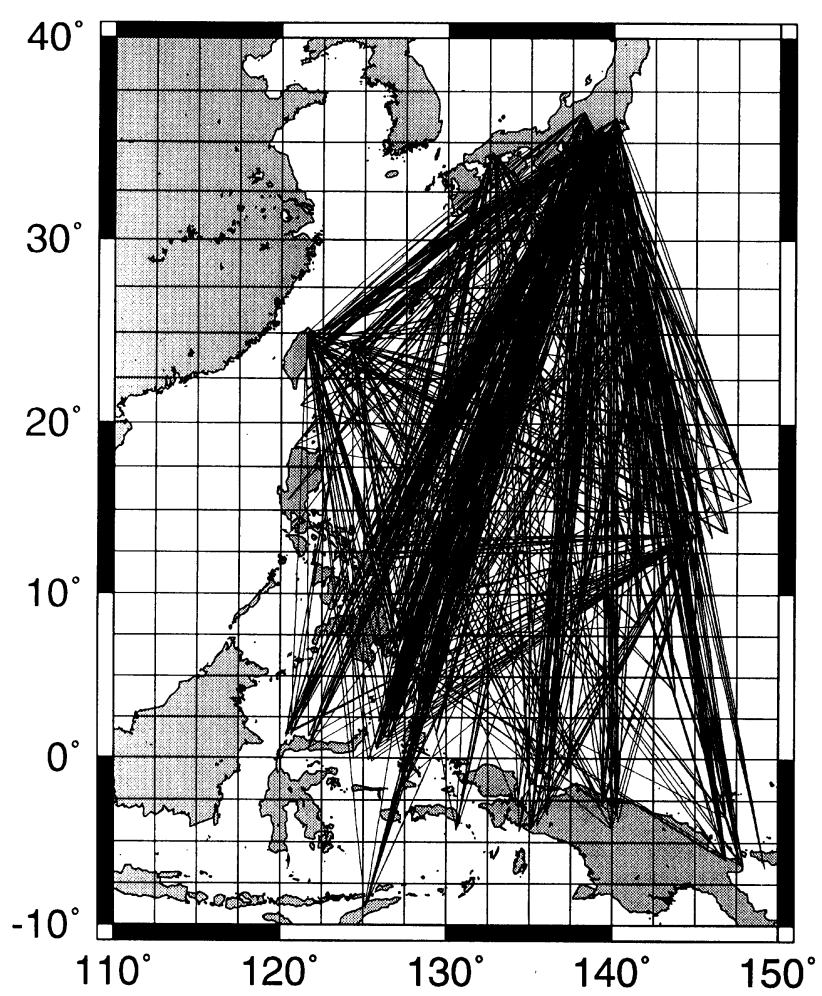

Fig. 4. Path coverage for the tomographic analysis.

parameterization is adopted, where laterally homogeneous structure is assumed inside of each block. The block size was set to 2.5 degree square. Each surface wave propagation path was fixed to the great circle which includes both of the epicenter and the station.

Phase delay time with respect to the averaged phase velocity value for the $i$-th path is

$$
\delta t_{i}=\frac{\Delta}{C_{\mathrm{obs}}}-\frac{\Delta}{C_{\mathrm{ave}}}
$$

where $\Delta$ is a epicentral distance and $C_{\mathrm{obs}}$ and $C_{\mathrm{ave}}$ mean the observed and averaged phase velocity values, respectively. On the other hand, $\delta t_{i}$ can be also written in the following form:

$$
\delta t_{i}=\mathbf{m}^{\mathrm{T}} \mathbf{l}_{i}, \quad i=1,2,3, \cdots, N
$$

where

$$
\mathbf{m}=\frac{-\delta \mathbf{C}}{C_{\mathrm{ave}}^{2}}, \quad \delta \mathbf{C}=\left(\delta C_{j} ; j=1,2,3, \cdots, M\right)
$$

and

$$
\mathbf{l}_{i}=\left(l_{i j} ; j=1,2,3, \cdots, M\right) .
$$

$N$ is the number of the data and $M$ is the number of the blocks. $l_{i j}$ means the fractional path length of the $i$-th path in the $j$-th block and $\delta C_{j}$ is the phase velocity perturbation in the $j$-th block with respect to the average phase velocity in each period.

Equation (6) is the observational equation of our problem. This equation (6) is a linear problem so that we can directly solve it and obtain the model parameter $\mathbf{m}$.

To obtain smooth models, simple spatial smoothness constraints, which involve 2-D Laplacian, are introduced in this study. Assuming that a model parameter $m_{j}=m_{p, q}$ is related to the block which is located at the $p$-th longitude and the $q$-th latitude. The relationship between $j, p$ and $q$ is $j=p+(q-1) N_{x}$ where $N_{x}$ is the number of the blocks in each latitude. Our smoothness constraint is represented by the following equation,

$$
m_{p, q-1}+m_{p-1, q}+m_{p+1, q}+m_{p, q+1}-4 m_{p, q}=0 .
$$

This equation (9) is written in a matrix form as follows:

$$
\mathbf{D m}=\mathbf{0}
$$

where the matrix $\mathbf{D}$ is called as the roughness matrix, the $(i, j)$ element of $\mathbf{D}$,

$$
D_{i j}=\left\{\begin{aligned}
-4 & \{j ; j=i\} \\
1 & \left\{j ; j=i-N_{x}, i-1, i+1, i+N_{x}\right\} \\
0 & \text { otherwise }
\end{aligned}\right.
$$

gives the roughness between the $i$-th and the $j$-th model parameters. The roughness matrix $\mathbf{D}$ is a $M \times M$ square matrix and $M=N_{x} \times N_{y}$ where $N_{y}$ is the number of the block in the each longitude. Since our target region is spatially bounded, the element of $\mathbf{D}$ is 0 for the blocks which are not spatially adjacent to the $i$-th block.

After all, our observational equation to be solved is

$$
\left(\begin{array}{r}
\mathbf{G} \\
\alpha_{\mathrm{D}} \mathbf{D}
\end{array}\right) \mathbf{m}=\left(\begin{array}{r}
\delta \mathbf{t} \\
\mathbf{0}
\end{array}\right)
$$

where

$$
\mathbf{G}=\left(\mathbf{l}_{1}, \mathbf{l}_{2}, \cdots, \mathbf{l}_{i}, \cdots, \mathbf{l}_{N}\right)^{\mathrm{T}} .
$$

The vector $\mathbf{l}_{i}$ is the same as Eq. (8) and the elements of $\delta \mathbf{t}$ is described in Eq. (5). The solution is estimated in least square sense as follows:

$$
\hat{\mathbf{m}}=\left(\mathbf{G}^{\mathrm{T}} \mathbf{G}+\alpha_{\mathrm{D}}^{2} \mathbf{D}^{\mathrm{T}} \mathbf{D}\right)^{-1} \mathbf{G}^{\mathrm{T}} \delta \mathbf{t} .
$$

The smoothing parameter $\alpha_{\mathrm{D}}$ is often determined subjectively. To determine the parameters objectively, ABIC (Akaike Bayesian information criterion: Akaike, 1980) was used in this study. Zhang and Lay (1996) used the ABIC to obtain the optimum smoothing parameter in their global surface wave analysis. The optimum smoothing parameter which minimizes the ABIC value was determined for each period by grid search.

\subsection{Resolving power in the phase velocity mapping}

Figure 4 shows the path coverage of the tomographic analysis for Rayleigh wave. Since propagation paths cover most of the target region densely, our results are expected to have good resolution in the whole Philippine Sea region. Figures 5(a) and 5(b) show the resolution of our tomographic analysis for $40 \mathrm{~s}$ and $100 \mathrm{~s}$ Rayleigh waves, respectively. The resolution is quite good in most of the Philippine Sea, although it is poor in some blocks in the longer period (100 s). This is due to heavy smoothing required to minimize the ABIC in this period. Table 2 shows some examples of the results of the tomographic analysis. Variance reductions seem to be good at most of the periods especially in shorter periods, although they are not very good in longer periods. The 
RESOLUTION

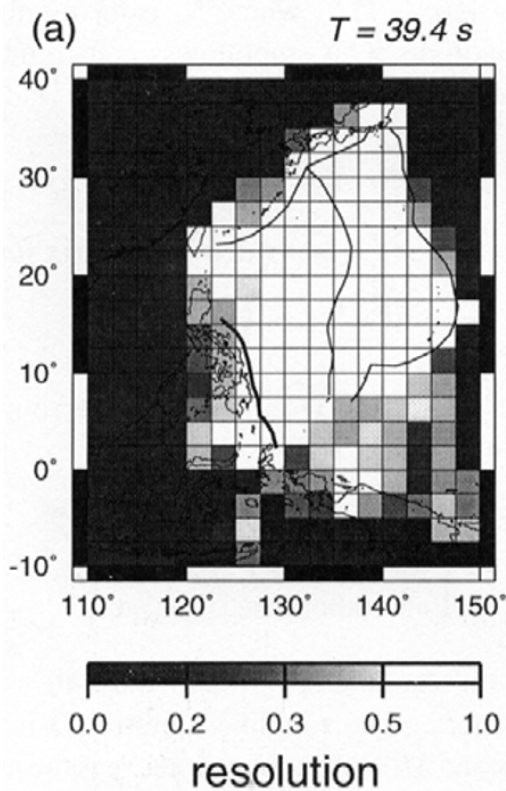

RESOLUTION

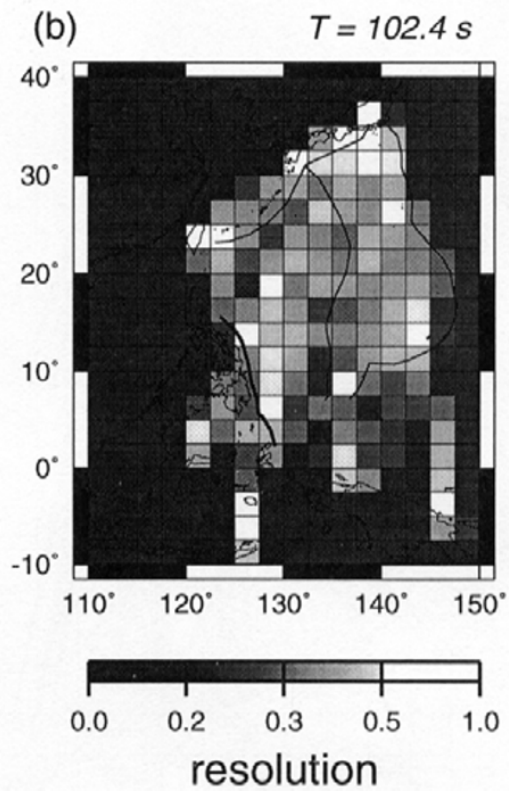

Fig. 5. Resolution of the tomographic analysis for (a) $40 \mathrm{~s}$ and (b) $100 \mathrm{~s}$. The diagonal elements of each resolution matrix are normalized by the maximum value and plotted at each block. White blocks are well resolved and grayed blocks are not well resolved.

root mean square residuals of the data are also tabulated in Table 2.

Figures 6(a)-6(c) show phase velocity distribution maps of Rayleigh waves for the period of $40 \mathrm{~s}, 60 \mathrm{~s}, 80 \mathrm{~s}$, respectively.

Figure 6(a) shows the phase velocity distribution of the Rayleigh wave for the period of $40 \mathrm{~s}$. In the shortest period range, 30-40 s very short wavelength (about 300-500 km) heterogeneities such as the low velocity at the north portion of the Kyushu-Palau Ridge, can be seen. Low velocity anomaly at the Mariana trough is clearly seen in this period range. There are also seen a low anomaly at the Okinawa trough, the Shikoku Basin and the northeast of the Luzon island, Philippines. Figure 7(a) shows the resolution for the block of the low anomaly at the north portion of the Kyushu-Palau Ridge. Since the trade-off between this block and others are very small, the anomaly seems to be a reliable result.

In the period range 50-70 s the Philippine Sea is roughly bounded by the Kyushu-Palau Ridge; high velocities in the western Philippine Sea and low velocities in the eastern Philippine Sea.

Figure 6(b) shows the typical phase velocity map in this period range. In the central western Philippine Sea, a low velocity patch is seen at the northeast of the Luzon islands, Philippines. The trade-off at this region is shown in Fig. 7(b). The resolution seems to be quite good, although blocks which have trade-off to the target spread broader than in the period of $40 \mathrm{~s}$ shown in Fig. 7(a). Note that the fastest region inside the Philippine Sea is located at the south of the West Philippine Basin and the slowest region is at the Shikoku Basin. These patterns are very similar to recent global phase velocity maps with high resolution (e.g. Ekström et al., 1997 and Trampert and Woodhouse, 1996), although the low anomaly in the
Table 2. Results of the tomographic analysis. The $\alpha_{\mathrm{D}}$ is the optimum smoothing parameter adopted for each period. The V.I. is the variance reduction of the inversion. The Res. is the root mean square residuals of the data.

\begin{tabular}{clcc}
\hline Period (s) & $\alpha_{\mathbf{D}}{ }^{2}$ & V.I. (\%) & Res. (s) \\
\hline 102.4 & $10^{12}$ & 10.78 & 14.9 \\
78.8 & $10^{11}$ & 26.19 & 11.3 \\
68.3 & $10^{11}$ & 30.81 & 9.8 \\
60.2 & $10^{11}$ & 33.03 & 9.0 \\
51.2 & $10^{11}$ & 36.36 & 8.2 \\
39.4 & $10^{10}$ & 55.14 & 6.9 \\
32.0 & $10^{10}$ & 61.28 & 6.6 \\
\hline
\end{tabular}

western Philippine Sea is not detected in the global studies.

Phase velocity distributions in the longest period range 80-100 s, which are represented by the phase velocity map for $80 \mathrm{~s}$ (Fig. 6(c)), show quite different characters compared to the shorter period ranges. The slightly low velocity dominates in most of the Philippine Sea except for the south of the West Philippine Basin and the eastern edge region. These features are quite similar to the recent global studies both in the pattern and the magnitude of the anomalies. At the south of the West Philippine Basin, the resolution is seems to be rather good in the period of $80 \mathrm{~s}$ (Fig. 7(c)), however it is not good in the period of $100 \mathrm{~s}$ (Fig. 7(d)). In the period of $80 \mathrm{~s}$, anomalies in the West Philippine Basin and Shikoku Basin 


\section{RAYLEIGH WAVE PHASE VELOCITY}
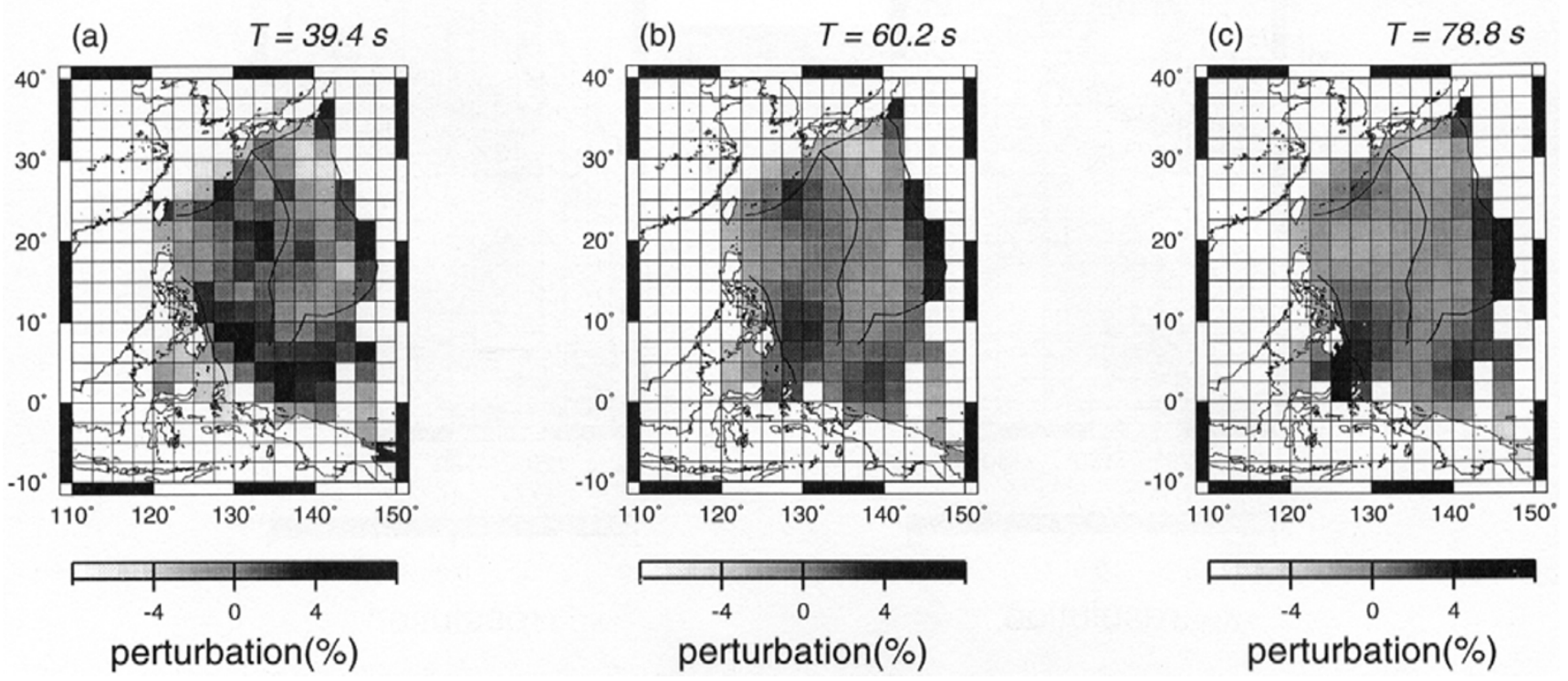

Fig. 6. Rayleigh wave phase velocity distribution map for the period of (a) $40 \mathrm{~s}$, (b) $60 \mathrm{~s}$ and (c) $80 \mathrm{~s}$. The perturbations with respect to the average value in this period were shown in percent. Only well resolved blocks are colored in this figure.

mentioned before are still seen.

The wavelength of the Rayleigh wave in the period of $100 \mathrm{~s}$ is about $400 \mathrm{~km}$, so our tomographic analysis seems to be able to resolve lateral heterogeneities with the scale length of $100 \mathrm{~km}$ or more. However, the phase velocity maps show heavily smoothed heterogeneous structure with much larger scale than expected from the Fresnel zones. The long-period maps also have smaller spectral amplitude than the short-period maps. These are partly because of the ambiguity in the phase velocity calculation of long-period Rayleigh waves. The path lengths of our data might be too short to determine precisely the long-period phase velocity. The calculated phase velocities in longer periods include relatively large errors, so smaller smoothing parameters little improve the data fit. Therefore, ABIC might select the heavily smoothing parameter.

\section{Shear Wave Velocity Structure}

\subsection{Eigenperiod inversion for shear wave velocity struc- ture}

Phase velocity distributions were converted to the phase velocity dispersion curve in each $2.5^{\circ} \times 2.5^{\circ}$ block which was used in the tomographic analysis. The phase velocity curve for each block was converted to the eigenperiods of the normal modes and the eigenperiods were inverted for 1-D spherical seismic structure with the method written as following where a laterally homogeneous structure assumed beneath each block. This inversion was operated for each block independently for each other. 1-D structures obtained for each block were arranged laterally. This arranged 1-D structures can be regarded as a 3-D structure in the Philippine Sea region.

The phase velocity dispersion curve drawn on the period- velocity plain was converted to eigenperiods of the fundamental modes with Jeans' formula,

$$
C=\frac{2 \pi R}{\left(n+\frac{1}{2}\right) T}
$$

where $C$ is the phase velocity, $R$ is the Earth's radius, $n$ is the order number, $T$ is the eigenperiod. In this study phase velocities of Rayleigh waves in the periods 30-100 s were converted to the eigenperiods of the fundamental spheroidal modes $S_{100}-S_{300}$. These eigenperiod data was inverted for 1-D shear wave velocity structure.

Our problem can be written as follows:

$$
\mathbf{d}=\psi(\mathbf{m})
$$

where data $\mathbf{d}$ consists of eigenperiods of fundamental modes calculated from the phase velocities and model $\mathbf{m}$ consists of a 1-D seismic structure. The data is related to model by a functional $\psi$. If the transverse isotropy was taken into account the 1-D seismic model $\mathbf{m}$ is written in the function of radius $r$ :

$$
\mathbf{m}(r)=\left(\rho(r), V_{\mathrm{PH}}(r), V_{\mathrm{SV}}(r), \xi(r), \phi(r), \eta(r)\right) .
$$

In Eq. (16), $\rho$ is the density, $V_{\mathrm{PH}}$ is the compressional wave velocity in horizontal plane, $V_{\mathrm{SV}}$ is the shear wave velocity along vertical axis of symmetry, $\xi=\left(V_{\mathrm{SH}} / V_{\mathrm{SV}}\right)^{2}$ is the anisotropic parameter for shear waves, $\phi=\left(V_{\mathrm{PV}} / V_{\mathrm{PH}}\right)^{2}$ is the anisotropic parameter for compressional waves, and $\eta$ is the other anisotropic element needed to fully describe the transversely isotropic medium.

Our data set consists of eigenperiods of only spheroidal modes and has poor resolution on the anisotropic parameters (e.g. Suetsugu and Nakanishi, 1987). Therefore, the isotropic 

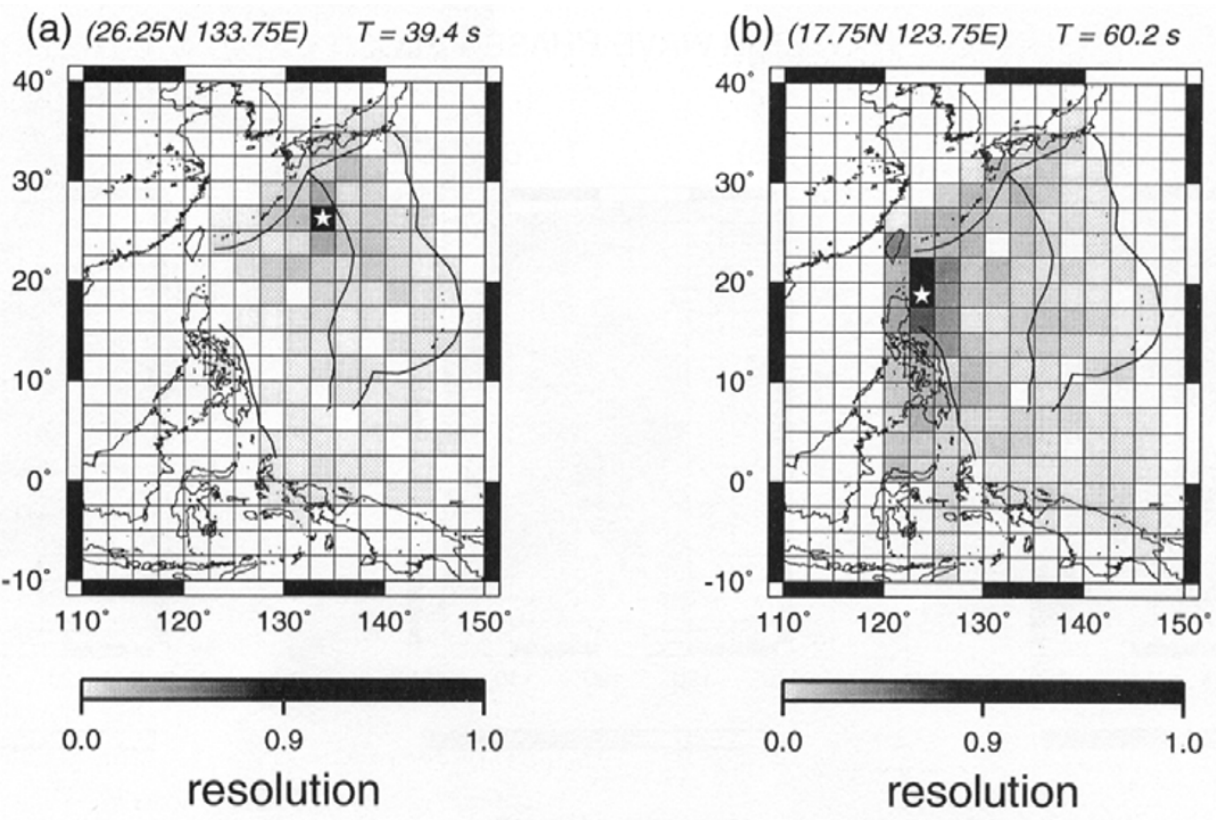

(c) $(8.75 \mathrm{~N} 128.75 \mathrm{E}) \quad T=78.8 \mathrm{~s}$

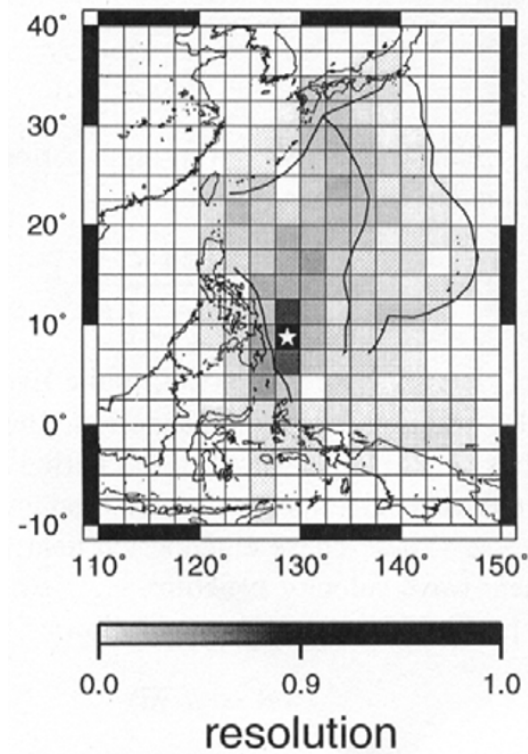

(d) $(8.75 \mathrm{~N} 128.75 \mathrm{E}) \quad T=102.4 \mathrm{~s}$

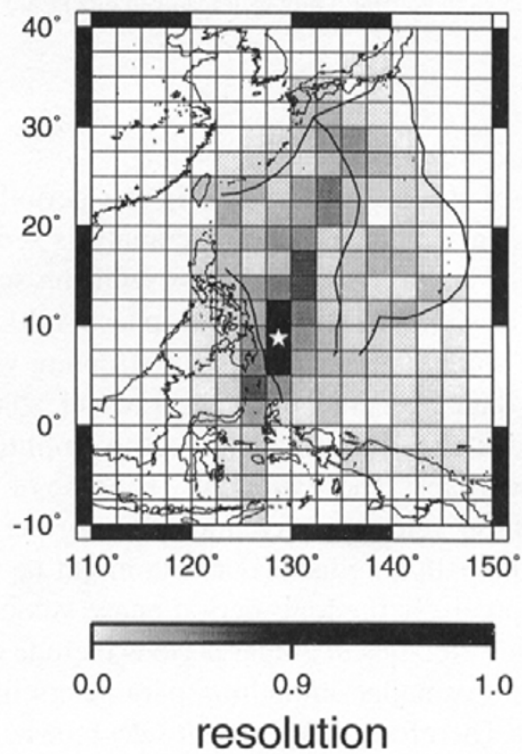

Fig. 7. Trade-off of the tomographic inversion for the block (a) at the southeast of the Daito Ridge in the period of $40 \mathrm{~s}$, (b) near the Luzon islands, Philippine in the period of $60 \mathrm{~s}$, (c) at the south of the West Philippine Basin in the period of $80 \mathrm{~s}$, (d) the same as (c) except for in the period of $100 \mathrm{~s}$. Each target block is indicated by white star.

parameterization was adopted in this study. The model $\mathbf{m}$ is written

$$
\mathbf{m}(r)=\left(\rho(r), V_{\mathrm{P}}(r), V_{\mathrm{S}}(r)\right) .
$$

Because the spheroidal modes are mainly contributed by the shear wave velocity $V_{\mathrm{S}}$, the values of the compressional wave velocity and density were fixed to initial values in the course of the inversion. Our data which consists of the spheroidal modes $\mathrm{S}_{100}-\mathrm{S}_{300}$ cannot resolve the structures in the depths shallower than $30 \mathrm{~km}$ and deeper than $200 \mathrm{~km}$. Hence, all the parameters at the sea and crustal depths and under $220 \mathrm{~km}$ depths were fixed during our inversion process.

5.1.1 A priori model covariance matrix $C_{m}$ In this inversion a priori covariance matrix for model $\left(\mathbf{C}_{\mathbf{m}}\right)$ were constructed fundamentally following Nataf et al. (1986) and Suetsugu and Nakanishi (1987).

Smoothness constraint of the depth variation of the model parameter was taken into consideration. Correlation length, $\Delta_{\text {cor }}(r)$ was introduced to control the smoothness of the parameter. If the errors of the model parameter are expected to distribute in a Gaussian shape with depth, the covariance 
(a)
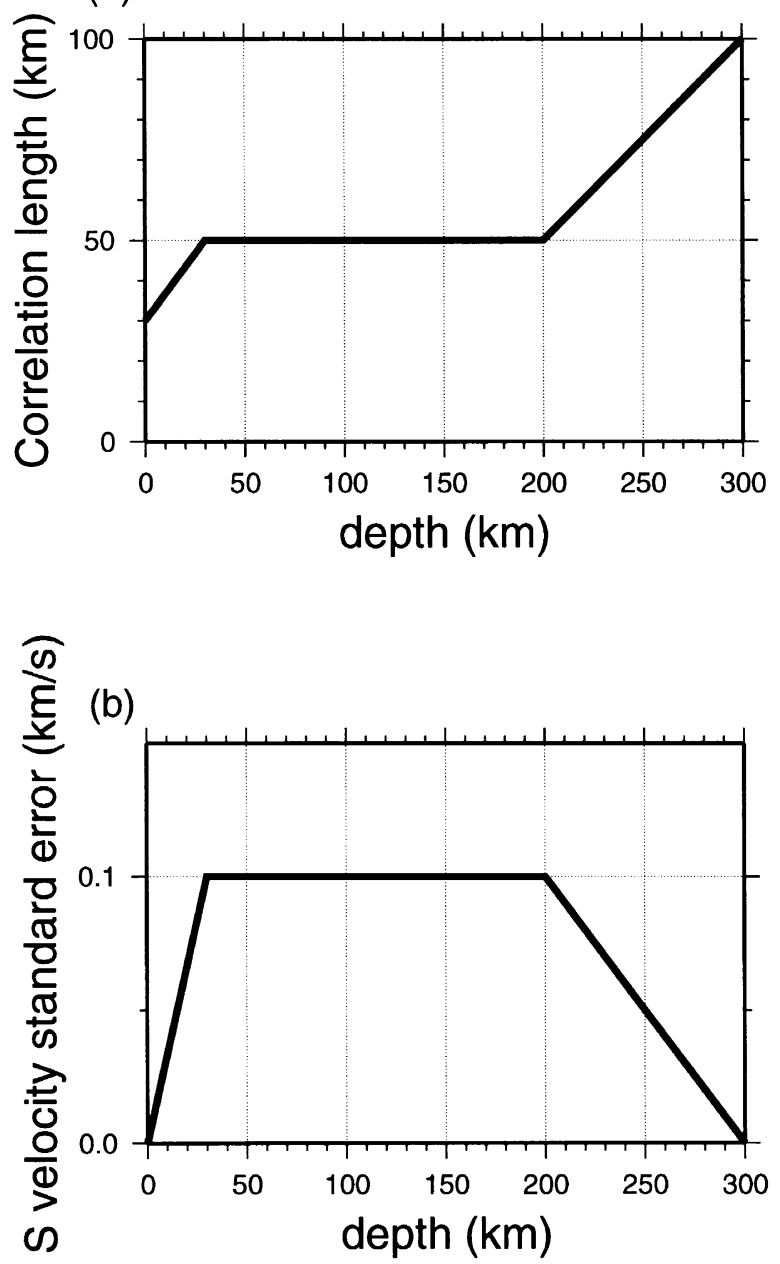

Fig. 8. A priori information in the eigenperiod inversion. (a) Correlation length adopted in the eigenperiod inversion. (b) A priori standard error of the shear wave velocity.

matrix for the parameter is expressed as

$$
C_{i j}=\sigma\left(r_{1}\right) \sigma\left(r_{2}\right) \exp \left(-\frac{\left(r_{1}-r_{2}\right)^{2}}{2 \Delta_{\text {cor }}\left(r_{1}\right) \Delta_{\text {cor }}\left(r_{2}\right)}\right)
$$

where $\sigma(r)$ is the a priori model error at radius $r, r_{1}$ and $r_{2}$ are the radii where the $i$-th and the $j$-th parameters were located, respectively. In Eq. (18) the correlation length and the a priori errors for shear wave velocity were required to determine the a priori covariance matrix for model. Following Suetsugu and Nakanishi (1987) these values were designed to have depth dependences. Figures 8(a) and 8(b) show the a priori values for the correlation length and the shear wave velocity error, respectively. Our eigenperiod data were produced by the Rayleigh wave phase velocities in the period range of 30-100 s, which was shorter than in Suetsugu and Nakanishi (1987). The shorter period range might also allow the depth resolution to be better. Therefore, the correlation length were set to have smaller value than Suetsugu and Nakanishi (1987). Smaller values were also chosen for the a priori shear wave velocity errors to stabilize the inversion.

5.1.2 A priori data covariance matrix $\mathbf{C}_{\mathbf{d}}$ The a priori covariance matrix for data $\left(\mathbf{C}_{\mathbf{d}}\right)$ was set to be a diagonal matrix whose elements are standard errors of the eigenperiods. Because eigenperiods were obtained from the phase velocity curves, the errors of the eigenperiods should be taken from errors of the phase velocities. Errors of the phase velocities were converted to the errors of the eigenperiods also using Jeans' formula (Eq. (14)).

In the tomographic inversion the posteriori errors of the model parameter $-\delta C / C_{\text {ave }}{ }^{2}$ (Eq. (7)) were evaluated from the square root of diagonal elements of the posteriori covariance matrix in the tomographic analysis. The phase velocity errors were evaluated from this posteriori model errors for the shear wave velocity analysis.

\subsubsection{Surface layer correction and initial models} This problem is also highly non-linear, and also embraces initial model dependence. Surface wave dispersions, or eigenperiods of normal modes are influenced by surface layer, especially in shorter period range. It is reported that this influence is still quite important for Rayleigh waves in the periods longer than $300 \mathrm{~s}$. Therefore, if shallow layer corrections are not included, misestimation should be brought to the upper mantle structure. For shallow layer correction, a global crust model CRUST5.1 (Mooney et al., 1998) was used in this study. This model consists of $5^{\circ} \times 5^{\circ}$ tiles in which crustal and upper-most mantle properties (layer thickness, $V_{\mathrm{P}}$ and $\left.V_{\mathrm{S}}\right)$ are described in 8 layers. The topography and the bathymetry are included as well. In the course of inversion, parameters were fixed in these shallow layers except for the sub-Moho's values. Because our eigenperiod data was obtained for each $2.5^{\circ} \times 2.5^{\circ}$ tile, the surface layer corrections are the same in each $2 \times 2$ blocks of our parameterization.

For the depths between the Moho and $220 \mathrm{~km}$, the initial models were assigned to have a uniform shear wave velocity of $4.3 \mathrm{~km} / \mathrm{s}$. Under the $220 \mathrm{~km}$ depth, the PREM model was used.

Now all the ingredients of our problem for 1-D seismic structure inversion were defined. The model parameters were corrected iteratively with the following equation:

$$
\begin{aligned}
\mathbf{m}_{i+1}= & \mathbf{m}_{0}+\mathbf{C}_{\mathbf{m}} \mathbf{G}_{i}^{\mathrm{T}}\left(\mathbf{C}_{\mathbf{d}}+\mathbf{G}_{i} \mathbf{C}_{\mathbf{m}} \mathbf{G}_{i}^{\mathrm{T}}\right)^{-1}\left(\mathbf{d}-\psi\left(\mathbf{m}_{i}\right)\right. \\
& \left.+\mathbf{G}_{i}\left(\mathbf{m}_{i}-\mathbf{m}_{0}\right)\right)
\end{aligned}
$$

where $\mathbf{m}_{i}$ means $i$-th iterated model. $\mathbf{G}_{i}$ which indicates the partial derivatives of the eigenperiods with respect to the $i$-th iterated model parameters were calculated using the program package DISPER80 (Saito, 1988).

\subsection{Three-dimensional shear wave velocity structure}

Figures 9(a)-9(d) show examples of the 1-D shear wave velocity structure obtained by the eigenperiod inversion for the southern West Philippine Basin, southeast of the Daito ridge, Parece Vela Basin, and Mariana Trough, respectively. The data fittings are also shown in the figures. Each data was well explained by the obtained structure at least within error-bars.

Figures 10(a)-10(d) show the distribution map of the shear wave velocity at the depth of $60 \mathrm{~km}, 80 \mathrm{~km}, 100 \mathrm{~km}, 150 \mathrm{~km}$, respectively. These figures show the $S$ velocity perturbations with respect to the average value in the Philippine Sea at each depth.

In the shallow depth range $(40-60 \mathrm{~km})$, represented by the depth of $60 \mathrm{~km}$ in Fig. 10(a), lateral heterogeneities with 
(a) S wave velocity $(\mathrm{km} / \mathrm{s})$

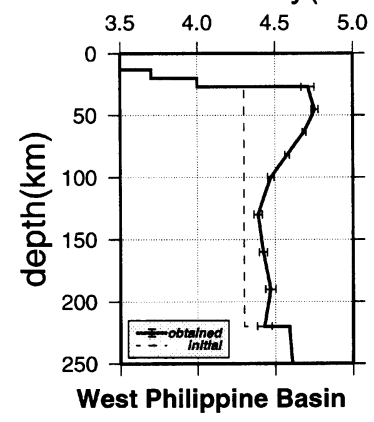

Data fit

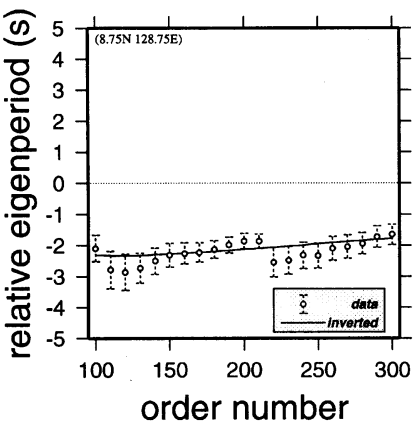

(c) S wave velocity $(\mathrm{km} / \mathrm{s})$

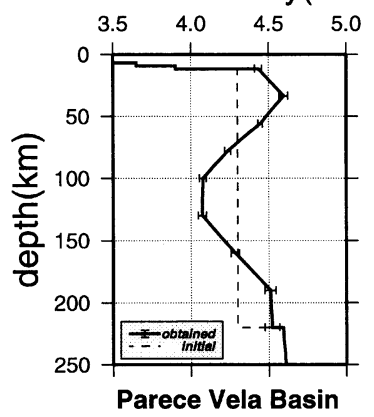

Data fit

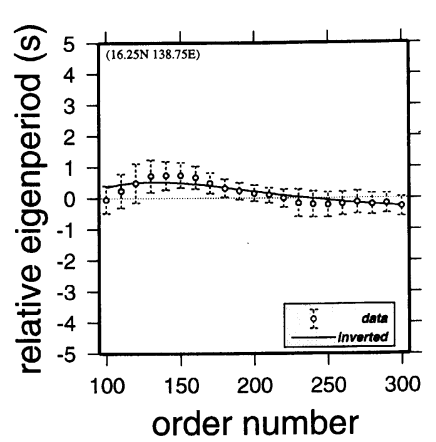

(b) S wave velocity $(\mathrm{km} / \mathrm{s})$

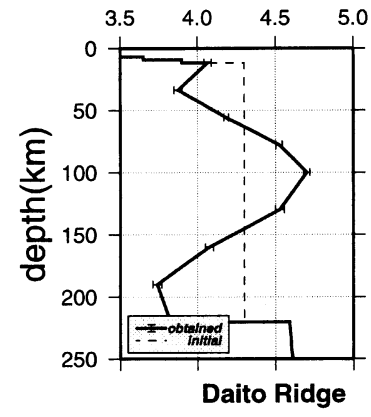

Data fit

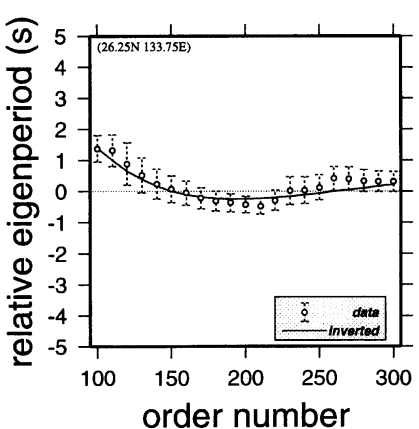

(d) $\mathrm{S}$ wave velocity $(\mathrm{km} / \mathrm{s})$

Data fit

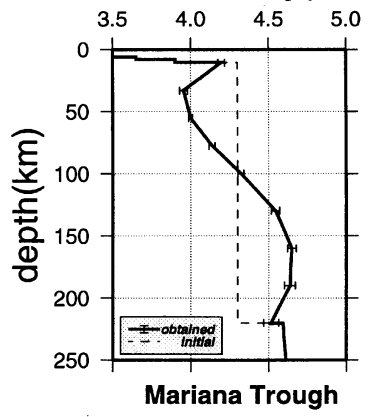

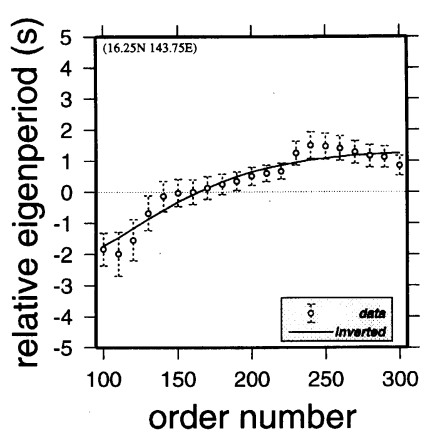

Fig. 9. Examples of the 1-D inversion. (a) for the block in the West Philippine Basin, (b) for the block in the Daito Ridge, (c) for the block in the Parece Vela Basin, (d) for the block in the Mariana Trough. The left figure shows the obtained 1-D shear wave velocity structure with the thick solid line. Error bars are the posteriori standard errors for each depth grid. The initial model is also indicated with the dashed line. The right figure shows the data fit of the inversion. Open circles with dashed error bars are the data and the solid line is eigenperiods predicted by the obtained model. Eigenperiods relative to the initial model are illustrated in this figure. Error bars are a priori errors of the data.

short wavelength can be seen in the same way as the Rayleigh wave phase velocity distribution in the period of $30-40 \mathrm{~s}$. The magnitude of the velocity perturbation is large and the maximum value of the perturbation reaches $10 \%$. The Okinawa trough and the Mariana trough indicate low shear velocities and the Shikoku Basin also has low velocity anomaly. The central portion of the Philippine Sea generally shows high anomaly in these depths.

At the depth of $80 \mathrm{~km}$ (Fig. 10(b)), the Kyushu-Palau Ridge is a boundary between high velocity anomaly in the western part and low velocity anomaly in the eastern part, which is similar to the Rayleigh wave phase velocity distribution in the periods 50-70 s. In the western high velocity area, the low velocity patch is also seen around the central basin ridge. The velocity perturbations are within about $\pm 5 \%$ in most of the Philippine Sea except for the Shikoku Basin, where the shear wave velocity is slow in $8 \%$.

At the depth of $100 \mathrm{~km}$ (Fig. 10(c)) most of the features are similar to that of $80 \mathrm{~km}$ depth (Fig. 10(b)), however the high velocity region in the western Philippine Sea is divided into two areas; the Daito and the Oki-Daito Ridges to the north and the southern West Philippine Basin to the south. The amplitudes of the low velocity anomaly reaches $10 \%$ in the slowest Shikoku Basin.
As seen in Fig. 10(d), most of the Philippine Sea has slightly low shear wave velocity $(5 \%$ or less) at the depth of $150 \mathrm{~km}$. On the contrary the edge regions of the Philippine Sea indicate high velocity anomaly.

\section{Discussions}

The short wavelength heterogeneities seen at the shallow depths might be related to the complicated surface structures in the Philippine Sea region, however the shear wave distributions were not completely explained by the surface structure. This is partly due to the lack of the resolution of our data at the shallow depths. Another reason might be the incompleteness for the surface layer corrections. The surface layer corrections were given in every $5^{\circ} \times 5^{\circ}$ block, which is rough in scale compared with the parameterization used in our tomographic analysis. Figure 9(b) shows the low velocity zones at the depths of $30-50 \mathrm{~km}$. This might reflect the anomalously thick crust beneath the Daito Ridge (Murauchi et al., 1968). More detail informations for the surface structures by refraction surveys or short period surface waves are needed to settle this problem.

At the depths of $80-100 \mathrm{~km}$, the shear wave velocities are related to the surface tectonic features. The older western Philippine Sea indicates the fast shear wave velocity, 
(a)

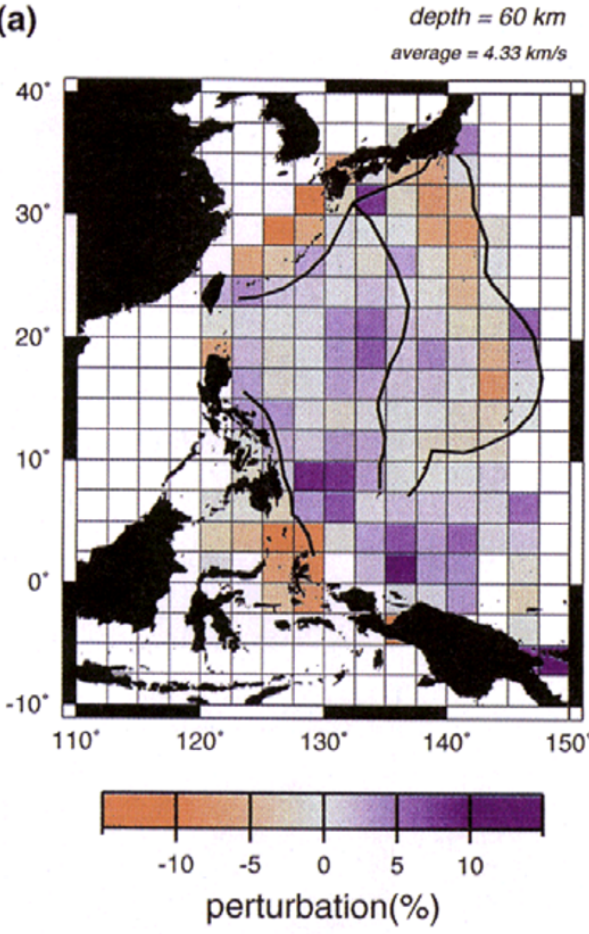

(c)
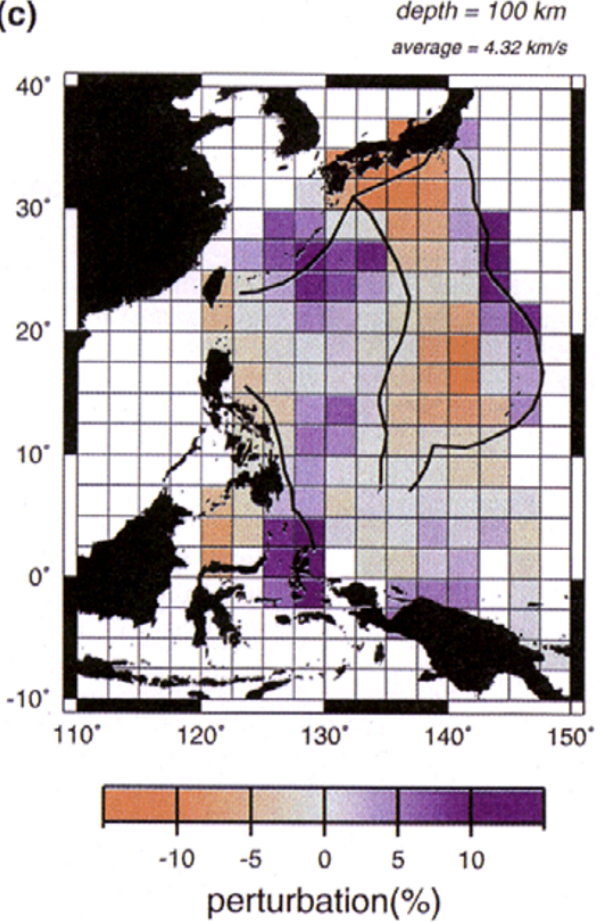

(b)

depth $=80 \mathrm{~km}$

average $=4.33 \mathrm{~km} / \mathrm{s}$
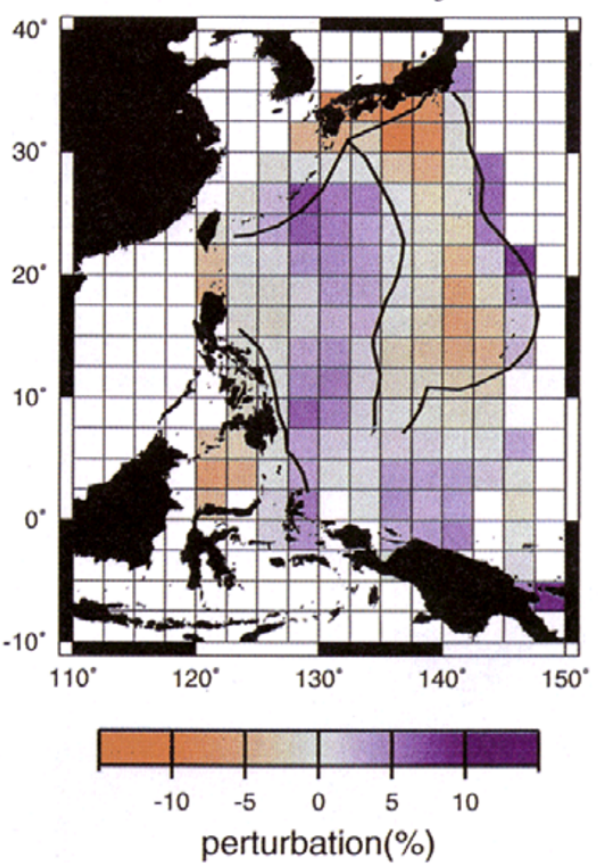

(d)

depth $=150 \mathrm{~km}$

average $=4.32 \mathrm{~km} / \mathrm{s}$

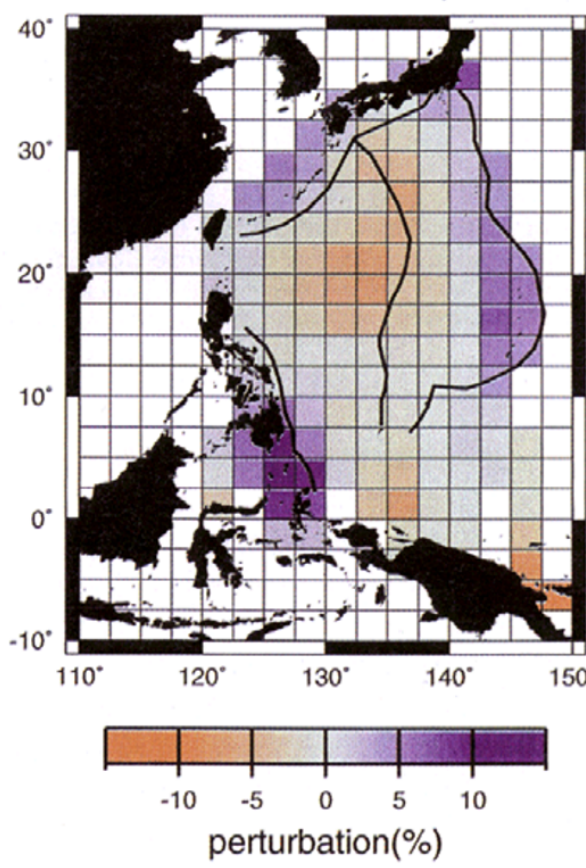

Fig. 10. Shear wave velocity distribution at the depth of (a) $60 \mathrm{~km}$, (b) $80 \mathrm{~km}$, (c) $100 \mathrm{~km}$, (d) $150 \mathrm{~km}$. The perturbations with respect to the average value in each depth were shown in percent.

and younger eastern Philippine Sea shows the slow shear wave velocity. This contrast reflects the difference of the lithosphere thickness between these two areas according to the different sea floor age. The area near the central basin ridge in the West Philippine Basin has slow shear velocity against the dominant fast velocities in the western Philippine Sea. The low anomaly indicates that the youngest portion in the West Philippine Basin exists around this area. This is consistent with the fact that this basin was formed by the spreading at the central basin ridge. In the West Philippine Basin, the two high velocity regions which are derived by the central basin ridge might have the thick lithosphere extending to $100 \mathrm{~km}$ or more depths. Lebedev et al. (1997) reported quite similar features at the depth of $50 \mathrm{~km}$. However, at the depth of $100 \mathrm{~km}$ in the Lebedev's web page (http://geo.princeton.edu/grads/ 
(a)

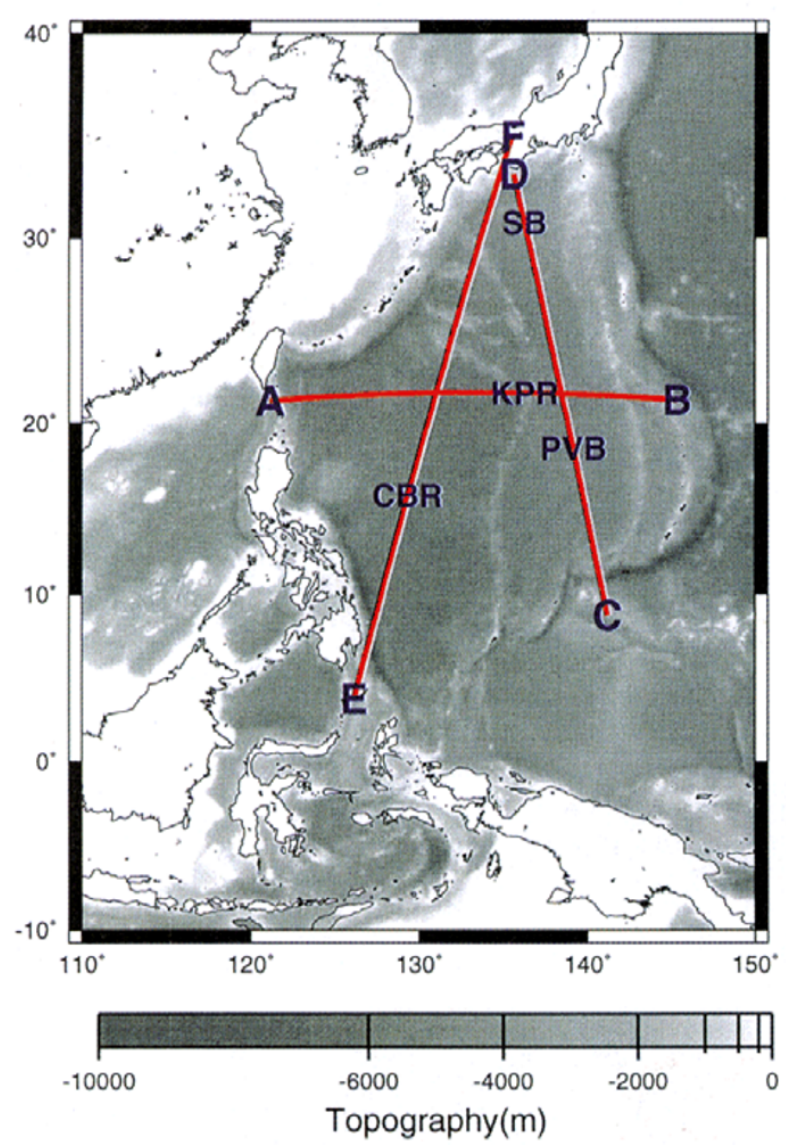

(b)

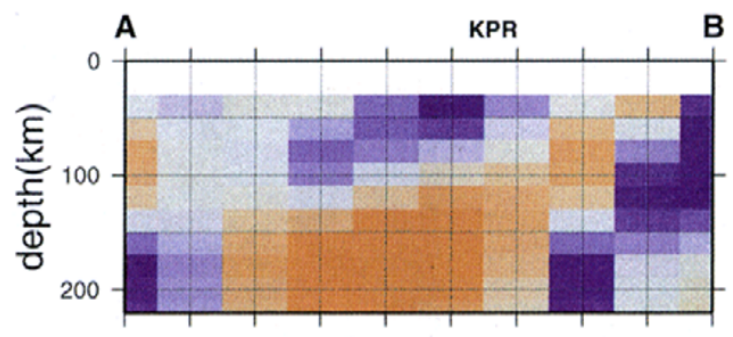

(c)

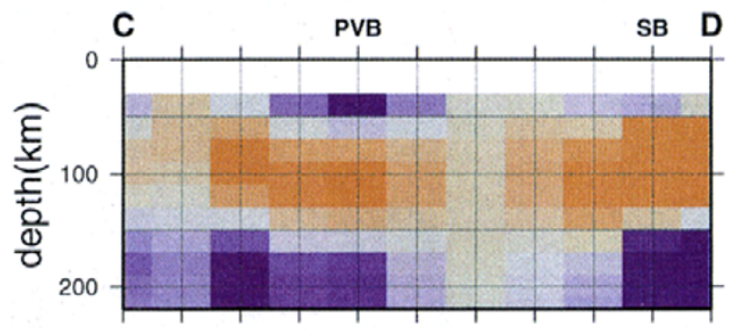

(d)
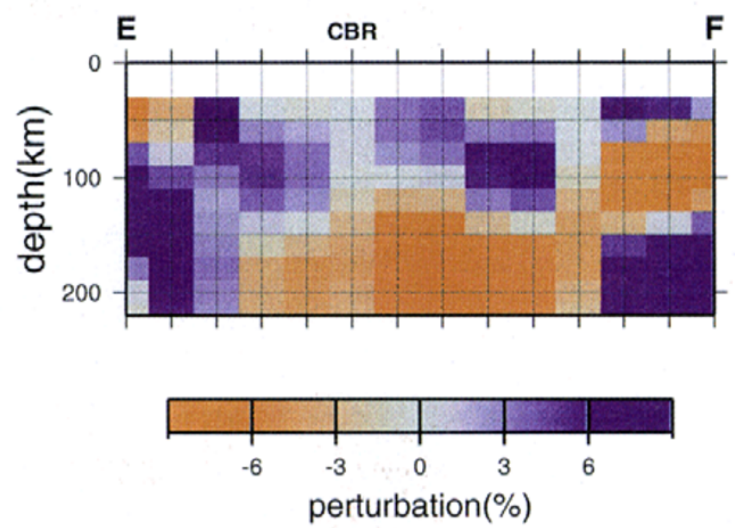

Fig. 11. Cross section of the shear wave velocity. (a) The location of the great circle, (b) EW cross-section for the great circle A-B across the central Philippine Sea, (c) NS cross-section for the great circle C-D across the eastern Philippine Sea, (d) NS cross-section for the great circle E-F across the western Philippine Sea. KPR, PVB, SB and CBR represents the Kyushu-Palau Ridge, Parece Vela Basin, Shikoku Basin and central basin ridge, respectively. The convention to represent the shear wave velocity is same as Fig. 10.

lebedev/PS96.html) the high velocity anomalies are not seen in their results except for the narrow portion in the south western edge of the West Philippine Basin.

At 150-200 km depths, the shear wave velocity distributions reflect the large scale tectonic features. At the $150 \mathrm{~km}$ depth the high velocity region around the Okinawa Island reflects the subducting Philippine Sea plate, and high velocities along the Mariana Trench reflect the subduction of the Pacific plate. The low velocity anomaly is dominant in most of the Philippine Sea at the depth of the $150 \mathrm{~km}$, although it is weak. This is consistent with the results of Lebedev et al. (1997). Similar low anomalies are reported in the southwest Pacific region by $\mathrm{Xu}$ and Wiens (1997). They mentioned that the South Fiji Basin which is an inactive back arc basin shows much slower upper mantle velocity. One of the reason of the low velocity anomaly might be due to the mantle return flow caused by the subduction of the Pacific plate. The slow anomaly in the Philippine Sea might have the relation to the fact that Philippine Sea is also a back arc basin.

Figures 11(b)-11(d) show cross-sections of the shear wave velocities along some particular great circle indicated in Fig. 11(a). Figure 11(b) shows an east to west cross-section of the central portion of the Philippine Sea. At depths shal- lower than $100 \mathrm{~km}$, the difference between the western and the eastern regions is clearly seen. The western area, which is the northern region of the West Philippine Basin, has high velocity while the western area, which is the northern region of the Parece Vela Basin, has low velocity. On the contrary below the $100 \mathrm{~km}$ depth, the difference is not seen between the two regions, although the subducting slab with high velocity is remarked beneath the eastern edge. The low velocity anomaly is dominant under the depth of $100 \mathrm{~km}$, which might also suggest the existence of the mantle return flows.

Figure 11(c) is a north-south cross-section in the eastern Philippine Sea. In this region lateral heterogeneity seems to be weak along this line, however the south region, which is the Parece Vela Basin, and the north region, which is the Shikoku Basin, are separated. The velocity contrast between the high velocity layer, or lithosphere, and the low velocity layer, or asthenosphere, shows some difference between these two basins, although these two basins were formed at almost the same time. The Parece Vela Basin has sharp contrast compared to the Shikoku Basin. The thickness of the lithosphere in the Parece Vela Basin is evaluated to be 30$40 \mathrm{~km}$. This is consistent with the results of Senna et al. (1990) and Oda and Senna (1994). 
Figure 11(d) shows a north-south cross-section in the western Philippine Sea. Obviously the high velocities in the upper most mantle, which might reflect the lithosphere, have laterally heterogeneous distributions. The lithosphere might reaches to $100 \mathrm{~km}$ depth at the north of the central basin ridge and more than $100 \mathrm{~km}$ at the south of the western Philippine Basin. This lithosphere is much thicker than the estimations of the Senna et al. (1990) and Oda and Senna (1994), and our result prefers the estimation of Kato and Jordan (1998). Oda and Senna (1994) reported that the relationship between plate thickness and sea floor age in the Philippine Sea satisfied the plate cooling model for the Pacific ocean proposed by Kono and Yoshii (1975). The relationship is represented as follows

$$
h=7.55 \sqrt{t}
$$

where $h$ is the plate thickness in $\mathrm{km}$ and $t$ is the sea floor age in Ma. The sea floor age in the West Philippine Basin is $60 \mathrm{Ma}$ or less. If the relationship for Pacific plate is applied to the West Philippine Basin, the thickness of the lithosphere is estimated to be $60 \mathrm{~km}$ or less. In the West Philippine Basin, the thickness of the lithosphere cannot be explain by the plate cooling model for the Pacific ocean, although the thickness is hardly be constrained precisely from only surface wave data.

In the present study, anisotropic features are not taken into account. Both of the azimuthal and radial anisotropies are important to reveal past and present situation of the upper mantle. However, the azimuth coverage of our data is not enough to resolve the azimuthal dependence of the phase velocity in 2.5 degree block. Moreover, our data consist of only Rayleigh waves, and do not include Love waves, therefore, the radial anisotropy (transverse isotropy) was not be considered in this study. Incorporating Love wave data with the Rayleigh wave data will allow to investigate the anisotropic structure.

\section{Conclusions}

The upper mantle structure beneath the Philippine Sea was investigated with Rayleigh wave phase velocities in the periods 30-100 s. More than 900 Rayleigh wave phase velocity curves were obtained for this region with good path coverage. The phase velocity data were inverted for the phase velocity distribution maps in the Philippine Sea. The 2-D tomographic technique was adopted to construct the $2.5^{\circ} \times 2.5^{\circ}$ block phase velocity map for each period with no a priori regionalization. The phase velocity maps were inverted for the 3 -D shear wave velocity structure in the upper mantle down to $220 \mathrm{~km}$. The detail structure compared to the previous studies was obtained in this study.

In the shallow depths (40-60 km) lateral heterogeneities with short wavelength were seen in the shear wave velocity maps. This might be related with complicated surface structures. In the middle depths $(80-100 \mathrm{~km})$ the shear wave velocity was well correlated to the main tectonic features seen at the surface and well explained by the evolution history in the Philippine Sea. The older western Philippine Sea had higher shear wave velocities than the younger eastern Philippine Sea. In the western Philippine Sea the central basin ridge, which is the youngest in this area, showed the low velocity anomaly. This was supported by the fact that the Western Philippine Basin was formed in this area. In the depths $150-200 \mathrm{~km}$ the low velocity anomaly was dominant inside the Philippine Sea, which might suggest the existence of the mantle return flows. The velocity contrast at the lithosphere-asthenosphere boundary was different between the Shikoku Basin and Parece Vela Basin, although these two basins has the same sea floor age. The south portion of the West Philippine Basin had the thick lithosphere which cannot be explained by the plate cooling model.

Acknowledgments. The authors thank Profs. M. Ando and K. Hirahara for their valuable suggestions. The gratitude is given to $\mathrm{M}$. Kato for his helpful comments The authors are grateful to Profs. G. Ekström and J. B. Gaherty and H. Kawakatsu for their critical reading and valuable comments. The authors also thank the staffs at the broadband seismic stations used in this study for their continuous effort to maintain the observation.

\section{References}

Akaike, H., Likelihood and Bayes procedure, in Bayesian Statistics, edited by J. M. Bernado et al., pp. 141-166, Univ. Press, Valencia, Spain, 1980.

Cara, M., Filtering of dispersed wavetrains, Geophys. J. R. astr. Soc., 33, 65-80, 1973.

Dziewonski, A. M. and D. L. Anderson, Preliminary reference Earth model, Phys. Earth Planet. Inter., 25, 297-356, 1981.

Dziewonski, A. M., A. L. Hales, and E. R. Lapwood, Parametrically simple Earth models consistent with geophysical data, Phys. Earth Planet. Inter. 10, 12-48, 1975.

Ekström, G., J. Tromp, and E. W. F. Larson, Measurements and global models of surface wave propagation, J. Geophys. Res., 102, 8137-8158, 1997.

Iidaka, T., K. Suyehiro, and H. Kinoshita, Lateral heterogeneity of the upper mantle velocity structure in the northern Philippine Sea basin, J. Phys. Earth, 37, 147-153, 1989.

Kanamori, H. and K. Abe, Deep structure of island arcs as revealed by the surface waves, Bull. Earthq. Res. Inst. Univ. Tokyo, 86, 1001-1025, 1968

Kato, M. and T. H. Jordan, Seismic structure of the upper mantle beneath the Western Philippine Sea, Phys. Earth Planet. Inter., 1998 (submitted).

Kono, Y. and T. Yoshii, Numerical experiment on the thickening plate model, J. Phys. Earth, 23, 63-75, 1975.

Lebedev, S., G. Nolet, and R. D. van der Hilst, The upper mantle beneath the Philippine Sea region from waveform inversions, Geophys. Res. Lett., 24, 1851-1854, 1997.

Masters, G., T. H. Jordan, P. G. Silver, and F. Gilbert, Aspherical Earth structure from fundamental spheroidal-mode data, Nature, 298, 609-613, 1982.

Mooney, W. D., G. Laske, and T. G. Masters, CRUST 5.1: A global crustal model at $5^{\circ} \times 5^{\circ}, J$. Geophys. Res., 103, 727-747, 1998.

Murauchi, S., N. Den, S. Asano, H. Hotta, T. Yoshii, T. Asanuma, K. Hagiwara, K. Ichikawa, T. Sato, W. J. Ludwig, J. I. Ewing, N. T. Edgar, and R. E. Houtz, Crustal structure of the Philippine Sea, J. Geophys. Res., 73, 3143-3171, 1968.

Nataf, H. C., I. Nakanishi, and D. L. Anderson, Measurements of mantle wave velocities and inversion for lateral heterogeneities and anisotropy, J. Geophys. Res., 91, 7261-7307, 1986.

Oda, H. and N. Senna, Regional variation of surface wave group velocities in the Philippine Sea, Tectonophys., 233, 265-277, 1994.

Saito, M., DISPER80: A subroutine package for the calculation of seismic normal mode solutions, in Seismological Algorithms, edited by D. J. Doornbos, pp. 293-319, Academic Press, San Diego, 1988.

Seekins, L. C. and T. Teng, Lateral variations in the Structure of the Philippine Sea Plate, J. Geophys. Res., 82, 317-325, 1977.

Senna, N., H. Oda, and K. Seya, Regional variation of Rayleigh wave group velocities in the Philippine Sea Area, Zisin, 43, 91-100, 1990 (in Japanese with English abstract)

Seno, T. and S. Maruyama, Paleogeographic reconstruction and organ of the Philippine Sea, Tectonophys., 102, 53-84, 1984.

Shiono, K., I. S. Sacks, and A. T. Linde, Preliminary velocity structure of Japanese Islands and Philippine Sea from surface wave dispersion, Carnegie Inst. Washington Year Book, 79, 498-505, 1980.

Suetsugu, D. and I. Nakanishi, Three-dimensional velocity map of the upper 
mantle beneath the Pacific Ocean as determined from Rayleigh wave dispersion, Phys. Earth Planet. Inter., 47, 205-229, 1987.

Tarantola, A. and B. Valette, Generalized non-linear inverse problems solved using the least squares criterion, Rev. Geophys. Space Phys., 20, 219-232, 1982.

Trampert, J. and J. H. Woodhouse, Global phase velocity maps of Love and Rayleigh waves between 40 and 150 seconds, Geophys. J. Int., $\mathbf{1 2 3}$ 675-690, 1995.

Trampert, J. and J. H. Woodhouse, High resolution global phase velocity distributions, Geophys. Res. Lett., 23, 21-24, 1996.

$\mathrm{Xu}, \mathrm{Y}$. and D. A. Wiens, Upper mantle structure of the southwest Pacific from regional waveform inversion, J. Geophys. Res., 102, 27439-27453, 1997.

Zhang, Y. S. and T. Lay, Global surface wave phase velocity variations, $J$. Geophys. Res., 101, 8415-8436, 1996.

Y. Nakamura (e-mail: saru@rcep.dpri.kyoto-u.ac.jp) and T. Shibutani 